\title{
A INSTITUIÇÃO FORMAL E A NÃO-FORMAL NA CONSTRUÇÃO DO CURRÍCULO DE UMA ESCOLA DE TEMPO INTEGRAL
}

\author{
Helena Maria dos Santos Felício*
}

\begin{abstract}
RESUMO: Este trabalho analisa a construção do currículo de uma Escola de Tempo Integral, em um contexto educacional formado pela parceria entre duas instituições (formal e não-formal), com o intuito de identificar os desafios e as possibilidades de tal construção que apontem para uma concepção integral de educação. A investigação desenvolveu-se em uma perspectiva qualitativa, compreendendo observação, análise documental e entrevistas com os educadores das duas instituições. Da análise realizada, a partir da organização e do funcionamento da estrutura curricular e do desenvolvimento coletivo da profissionalidade, constatou-se que os desafios e as possibilidades para a construção de tal currículo só se tornam possíveis quando as instituições: superarem a distinção existente entre elas; assumirem a construção de um único currículo; realizarem um trabalho coletivo; se encorajarem a olhar criticamente para o seu cotidiano, sendo capazes de propor ações que sejam fruto de uma interação com a comunidade e a cultura onde atuam. Palavras-chave: Currículo. Educação Integral. Educação Formal e Não-Formal.
\end{abstract}

\section{FORMAL AND NON-FORMAL INSTITUTIONS IN THE CONSTRUCTION OF A FULL-TIME SCHOOL'S CURRICULUM}

ABSTRACT: This study analyzes the construction of a curriculum for a Full-time School, in an educational context formed by the partnership between two institutions (formal and non-formal), in order to identify the challenges and possibilities of such a construction that indicate an integral conception of education. The investigation was developed in a qualitative perspective, taking in observation, documental investigation and interviews with educators from the two institutions. The analysis established that, from the organization and the functioning of the curricular structure and the development of collective professionalism, the challenges and possibilities for the construction of such a curriculum only becomes possible when the institutions: overcome the distinction existent between them; take on the construction of one single curriculum; work collectively; encourage each other to look critically at their everyday routines, being capable of proposing actions that are fruit of the interaction with the community and the local culture.

Keywords: Curriculum. Integral Education. Formal and Non-Formal Education.

\footnotetext{
* Doutora em Educação pela Pontifícia Universidade Católica de São Paulo (PUC-SP) ; Professora Adjunta da Universidade Federal de Alfenas (UNIFAL-MG). e Pesquisadora do grupo de pesquisa: "Formação e processos educativos: sujeitos, práticas e culturas". E-mail: hsfelicio@gmail.com
} 


\section{Introdução}

O presente trabalho objetiva analisar alguns movimentos realizados para a construção do currículo da Educação de Tempo Integral, em um contexto educacional formado pela parceria entre duas instituições: uma escola, que compreende, neste trabalho a dimensão formal da educação, e uma instituição socioeducativa, que compreende a dimensão nãoformal da educação.

O tempo na escola é uma das temáticas que já suscitou inúmeros debates e pesquisas em diferentes contextos da educação brasileira, desde as primeiras décadas do século passado. Mais recentemente, nas décadas de 80 e 90 do século XX, algumas experiências de escola pública em tempo integral foram, emblematicamente, desenvolvidas no estado do Rio de Janeiro, nos CIEPs, e em âmbito nacional, nos CAICs ${ }^{1}$. No entanto, foi somente no final da década de 90, do século XX, que a Lei de Diretrizes e Bases da Educação Nacional (Lei n. 9394/96) evidencia, em seu artigo 34, a importância e a necessidade da educação escolar em tempo integral como uma das bases para o pleno desenvolvimento dos educandos.

A Escola de Tempo Integral, mesmo sendo um indicativo legal, a partir de 1996, vem sendo lentamente implantada nas redes públicas de educação, uma vez que esbarra com diversos problemas. Entre eles, destacamos os de ordem econômica, no que diz respeito ao aumento significativo de investimento que o sistema público precisa fazer para a manutenção da Escola de Tempo Integral; o de ordem estrutural, no que diz respeito à organização do espaço, do tempo e do currículo; e, de ordem profissional, o que diz respeito ao aumento de professores na escola, bem como a necessidade da valorização da docência e o estabelecimento de um plano de carreira docente que permitam aos professores também atuar em tempo integral, em um único estabelecimento de ensino.

Considerando que a quase totalidade das escolas públicas brasileiras organiza-se em diferentes turnos para o atendimento de uma população quantitativamente expressiva, o espaço das escolas não se mostra suficiente para atender em tempo integral os diferentes sujeitos que frequentam a escola, diariamente, em dois ou três turnos diferentes.

Outra questão que se mostra salutar diz respeito à qualidade do processo educativo oferecido pelas Escolas de Tempo Integral. Os proje- 
tos elaborados e desenvolvidos no Brasil evidenciam a necessidade de atrelar a expansão do tempo de permanência do educando na escola à melhoria da qualidade do ensino oferecido, quando explicitam o compromisso de criar oportunidades reais para que os educandos possam se desenvolver em sua plenitude; para que as escolas, efetivamente, garantam aos educandos um melhor processo para a aprendizagem e o desenvolvimento.

Uma das alternativas oferecidas para superação dessas questões, sobretudo no quesito espaço e tempo, é o estabelecimento de parcerias entre diferentes instituições que compreendam as dimensões formal e não-formal da educação, a fim de que a ampliação do tempo educacional na vida dos educandos seja garantida.

A escola, entendida como instituição formal, responsável por trabalhar os conhecimentos de diversas áreas, culturalmente selecionados no currículo escolar, é apenas uma das formas do processo educacional que não deve ser assumida de maneira exclusiva.

Com a escola coexistem muitos outros e variados mecanismos e ambientes educacionais que "não devem ser vistos necessariamente como opostos ou alternativos à escola, mas como funcionalmente complementares a ela. Esses recursos são, justamente aqueles que a partir de certo momento passaram a ser chamados de não-formais" (TRILLA, 2008, p. 18-19).

Em termos conceituais,

a "educação formal" compreenderia o sistema educacional altamente institucionalizado, cronologicamente graduado e hierarquicamente estruturado que vai dos primeiros anos da escola primária até os últimos da universidade; a “educação não-formal”, toda atividade organizada, sistemática, educativa, realizada fora do marco do sistema oficial, para facilitar determinados tipos de aprendizagem a subgrupos específicos da população, tanto adultos como infantis (COOMBS apud TRILLA, 2008, p. 32-33).

Dessa forma, a dimensão não-formal da educação é aquela que rompe com as determinações que caracterizam a escola e se constitui como um conjunto de processos, meios, instituições, com objetivos explícitos de formação não diretamente voltados à outorga dos graus próprios do sistema escolar.

Ainda, segundo Trilla (2008), a expansão das instituições nãoformais se dá, de maneira mais intensa, na segunda metade do século XX, 
em decorrência de fatores sociais, econômicos, tecnológicos, culturais, entre outros, que geram necessidades educacionais e possibilidades pedagógicas que diferem daquelas realizadas na escola.

As instituições não-formais, atualmente, apresentam um leque bem amplo de objetivos e trabalhos desenvolvidos, algo que se tornaria difícil sua nomeação. Entre eles, encontra-se grande número de instituições que atendem crianças e adolescentes no contraturno escolar ${ }^{2}$, oferecendo um leque de atividades voltadas para o desenvolvimento socioeducativo-cultural desses sujeitos.

A parceria estabelecida entre uma instituição não-formal com essas características e uma escola se instaura como o principal foco deste trabalho, sobretudo no que diz respeito à identificação de desafios e de possibilidades que tal parceria enfrenta para construir um currículo, a partir de duas instituições, que aponte para uma concepção integral de educação.

\section{A compreensão do currículo em uma perspectiva integral}

Os estudos de currículo entendido como forma de organização das experiências de ensino e de aprendizagem nas instituições educacionais (APPLE, 2006; GOODSON, 2008; MOREIRA; SILVA, 2001) apontam, a partir das características da contemporaneidade, a necessidade de expandir tais experiências para além dos conteúdos das diversas áreas de conhecimento, tradicionalmente trabalhados no contexto escolar, em disciplinas específicas, muitas vezes fragmentadas e com fronteiras rígidas.

Segundo Oliveira (2004), o currículo precisa ser entendido como uma criação cotidiana daqueles que fazem as instituições educacionais, como prática que envolve os processos interativos realizados por educandos e educadores, nas relações estabelecidas no cotidiano educacional, relacionado com as estruturas sociais e culturais que o produzem. Dessa forma, podemos entender como a construção do currículo no cotidiano escolar é influenciada e determinada pelas características do contexto socioeconômico-cultural em que as instituições estão inseridas.

Tal compreensão significa afirmar que a concepção processual de currículo nos leva a considerá-lo como resultado de diversas operações materiais desenvolvidas nas instituições educacionais; de diferentes ideias, 
princípios e concepções que lhe dão forma; bem como das peculiaridades das condições reais do contexto de seu desenvolvimento.

Se, por um lado, assumir o currículo como uma construção cultural e social demanda considerar e analisar os contextos (social, político, econômico, cultural e pedagógico) concretos que o moldam, por outro lado, entendê-lo como forma de organizar uma diversidade de práticas educativas no cotidiano educacional supõe a compreensão de que diferentes ações, vários sujeitos, múltiplas concepções, espaços e tempos distintos, diversos saberes/fazeres intervêm em sua configuração, no interior de certas condições concretas estabelecidas por interações culturais, sociais e institucionais.

É necessário afirmar, também, que o currículo é um mecanismo que tem como uma de suas funções favorecer a construção do conhecimento culturalmente selecionado, por uma política educacional, para ser trabalhado, sistematicamente, no processo de escolarização. Contudo, em termos de conteúdos e práticas, o currículo é algo que não pode esgotarse em elementos preestabelecidos, estáticos, formais, regulamentados, mas, "deve adquirir sua forma e significado à medida que vai interagindo com a cultura nos seus diferentes contextos" (PIRES, 2005, p. 59).

Dessa forma, podemos considerar o currículo em dois sentidos: como uma ação humana, aquilo que fazemos enquanto construtores do currículo no cotidiano educacional (ações, discursos, opções metodológicas, seleção de materiais, planejamento, organização de atividades, avaliações, intercâmbio com os educandos, entre outros) e os seus efeitos, ou seja, o que ele produz em nós (visão de mundo, concepção de sociedade, de conhecimento, referencial para autonomia, cidadania, emancipação, relações interpessoais, entre outros).

Esses dois sentidos contribuem para assumirmos o processo de construção do currículo como práxis; ou seja, uma atividade teórico-prática que apresenta uma face ideal (teórica) e uma face material (prática) ajustada aos objetivos que visam à transformação da realidade. Em outras palavras, a unidade entre teoria e prática é condição sine qua non para entendermos o currículo como práxis, a fim de que o seu significado não se resuma a uma atividade teórica que não se materializa ou a uma atividade prática sem a produção de finalidades e conhecimentos que caracteriza a atividade teórica.

Olhar, sentir, captar, presenciar o currículo construído no cotidiano educacional, com essa perspectiva, supõe considerar que em sua 
construção inúmeras ações e intervenções, teorias e concepções colaboram para sua configuração e lhe conferem significado real no momento histórico de sua materialização efetivada no cotidiano educacional (SACRISTÁN, 2000).

Considerado como uma práxis, observa-se, na construção do currículo no cotidiano educacional, constantemente, o movimento dialético entre o formal e o informal; entre o prescrito e o vivenciado; entre a regulação e a emancipação. Ou seja, se, por um lado, o currículo oficial apresenta diversos objetivos a serem atingidos pelo processo educativo objetivos esses quase sempre preconizados por uma cultura dominante que valoriza os princípios sustentadores dessa cultura em detrimento de outras -, por outro lado, o cotidiano apresenta situações emergentes que demandam uma prática pedagógica que vai ao encontro de suas necessidades.

Nesse sentido, a concepção da construção de um currículo integral está para além da ampliação da permanência do educando nas instituições educacionais, desenvolvendo um rol de atividades curriculares que enriqueçam a vivência dos educandos - o que é significativo também. Contudo, o currículo integral deve ser compreendido como um único processo, construído a partir de uma perspectiva interdisciplinar e transdisciplinar, tendo em vista a interdependência entre as áreas de conhecimento (SOUZA, 2010) e instituições - e destes com o contexto social que garanta a formação plena do educando.

Esse ideal da formação plena garantido por um processo educativo que propicie ao educando desenvolver-se como pessoa e cidadão é preconizado por diversos autores como resultado almejado por uma educação integral (GUARÁ, 2009; COELHO, 2009; MOLL, 2010). Ou seja, aquela que considera o educando como sujeito do processo de ensino e de aprendizagem, que possui uma singularidade própria e que apresenta necessidades específicas para o seu desenvolvimento e sua real inserção na sociedade contemporânea (GONÇALVES; PETRIS, 2006).

Recentemente, o Decreto 7.083/2010 apresenta como uns dos princípios para a educação integral a questão da articulação das disciplinas curriculares com diferentes campos de conhecimento e práticas socioculturais e a constituição de territórios educativos para o desenvolvimento de atividades de educação integral, por meio da integração dos espaços escolares com outros espaços que podem ser considerados como educativos. 
Tal decreto fortalece, ainda mais, as parcerias que já vêm sendo estabelecidas entre instituições formais e não-formais para o desenvolvimento da educação integral, ao mesmo tempo que permite que essas parcerias sejam vistas como possibilidades de garantir a "Escola de Tempo Integral" prevista por lei.

Essas parcerias não podem ser configuradas na perspectiva de afirmar a cisão, ainda existente, entre a educação formal e a educação nãoformal, como se a primeira fosse legítima, com maior valor, em detrimento da segunda, considerada menos importante. A questão de uma parceria dessa natureza supõe "defender um continuum entre as ações e experiências vividas nessas duas esferas de educação" (ARANTES, 2008, p. 8) que propiciam aprendizagens diferentes, compreendendo o processo educacional para além da educação formal.

Esse continuum preconizado pelas ações desenvolvidas entre as instituições formal e não-formal, para o desenvolvimento de uma educação de tempo integral, supõe superar a visão, afirmada pela instituição formal, de uma relação de reforço e de colaboração que a instituição não-formal deve oferecer à escolarização formal. Segundo Trilla (2008, p. 47), “a educação integral é um nobre ideal que há de ter em vista todas e cada uma das instâncias educacionais, mas para ser compartilhadas entre todas".

Assim, pensar na construção de um currículo integral a partir da parceria entre instituições formal e não-formal supõe, segundo Coelho (2004), superar a fragmentação das disciplinas trabalhadas na escolarização formal e integrar, nas atividades - formais e naquelas que são organizadas no contraturno escolar pela instituição não-formal -, o conhecimento e as experiências necessários para a formação do cidadão, mediante o redimensionamento da proposta pedagógica que considere não apenas a gestão de um contraturno, mas a organização de uma proposta curricular integrada e articulada em um projeto político-pedagógico mais amplo. 


\section{A dimensão formal e não-formal na construção do currículo para a Escola de Tempo Integral}

O contexto educacional investigado está instalado em um conjunto habitacional, construído, especialmente, para abrigar os moradores de três favelas participantes do programa de desfavelização desenvolvido pelo poder público de São José dos Campos, interior de São Paulo, a partir de 1999.

Esse conjunto habitacional foi projetado para abrigar 453 unidades habitacionais de $32 \mathrm{~m}^{2}$ cada, uma escola, um centro comunitário, uma quadra poliesportiva, uma creche, uma Unidade Básica de Saúde e uma Unidade Fundhas ${ }^{3}$.

Após a transposição dos moradores das favelas para o conjunto habitacional, a escola foi a primeira instituição pública que iniciou seu funcionamento, em 2004. Contudo, o primeiro ano de funcionamento foi o suficiente para mostrar que a escola, da forma como estava instituída, em termos de currículo, não respondia às necessidades dos educandos e nem respeitava a cultura daquele contexto.

$\mathrm{O}$ enfrentamento vivenciado nesse primeiro ano evidenciou o conflito entre os dois elementos fundantes que convivem na sociedade, como afirma Castoriadis (1995): o instituído e o instituinte. O instituído, representado pelas normas, regras, organização do trabalho pedagógico, definidos a priori pelo poder público, e o instituinte, como elemento que convive com o instituído, provocando, muitas vezes, a redefinição das normas e dos valores.

A redefinição do atendimento educacional é realizada pela parceria, estabelecida a partir de 2005, entre a escola de ensino regular público e a instituição de educação não-formal, que trabalha com processos educativos com a intenção de desenvolver ações, em parceria com a escola regular. Tal parceria foi concebida pelas duas instituições (formal e nãoformal) como a possibilidade de desenvolver um processo educativo na dimensão da educação integral.

O recorte apresentado neste trabalho diz respeito à análise da construção do currículo para a Escola de Tempo Integral a partir da experiência de parceria entre a instituição formal e a não-formal. Tal construção é, aqui, assumida sob duas perspectivas, a saber: a da organização e do funcionamento da estrutura curricular; e a do desenvolvimento coletivo da profissionalidade. 


\section{A organização e o funcionamento da estrutura curricular}

No que diz respeito à organização e ao funcionamento da estrutura curricular, o Projeto Político-Pedagógico da escola, enquanto instituição formal, previa, antes da parceria com a instituição não-formal, a seguinte estrutura curricular para os primeiros anos do ensino fundamental, comum a todas as escolas da rede de ensino municipal:

\section{QUADRO 1:}

PROPOSTA CURRICULAR VIGENTE NA ESCOLA EM 2004

\begin{tabular}{|c|c|c|c|c|c|}
\hline \multicolumn{2}{|c|}{ COMPONENTES CURRICULARES } & \multicolumn{4}{|c|}{$\begin{array}{c}\text { CICLO I } \\
\text { NÚMERO DE AULAS/SEMANA }\end{array}$} \\
\hline & & $1^{\circ}$ & $2^{\circ}$ & $3^{\circ}$ & $4^{\circ}$ \\
\hline BASE & Português & 07 & 07 & 06 & 06 \\
\hline NACIONAL & História & 02 & 02 & 03 & 03 \\
\hline \multirow[t]{6}{*}{ comum } & Geografia & 02 & 02 & 03 & 03 \\
\hline & Ciências & 03 & 03 & 04 & 04 \\
\hline & Matemática & 07 & 07 & 05 & 05 \\
\hline & Ed. Física & 02 & 02 & 02 & 02 \\
\hline & Artes & 02 & 02 & 02 & 02 \\
\hline & TOTAL DA BASE COMUM & 25 & 25 & 25 & 25 \\
\hline
\end{tabular}

Essa estrutura é tipicamente o modelo de uma organização curricular formal, fragmentada e compartimentalizada, cujo objetivo está centrado na veiculação de informações, e não na construção do conhecimento.

Mesmo sendo uma prescrição legal, o estabelecimento de determinado número de aulas por semana das diferentes áreas do conhecimento evidencia, também, que algumas áreas específicas, como Português e Matemática, são consideradas mais importantes do que as demais, consequentemente, demandam número maior de aulas por semana.

De modo geral, essa forma de organização curricular pressupõe, implicitamente, que existe um único perfil de formação desejada para os educandos, em que a mesma estratégia de ensino é utilizada para a compreensão de qualquer informação, o conhecimento veiculado no ambiente educacional é totalmente descontextualizado e a repetição de algumas informações decoradas é suficiente para a realização de uma avaliação, em que o educando deve apenas demonstrar o que memorizou a respeito de determinado componente curricular. 
Contudo, essa estrutura curricular não respondeu às necessidades educacionais daqueles educandos, que, em suas escolas de origem (próximas às favelas onde moravam), eram vítimas da exclusão no próprio processo educacional em função do comportamento agressivo, consequentemente da não aprendizagem e do não comprometimento com o seu processo educacional, sendo consideradas como crianças e adolescentes que fazem parte de um grupo pertencente ao denominado "fracasso escolar".

A partir do momento em que todos esses educandos são transferidos para a mesma escola, em função das mudanças de moradia decorrente do processo de desfavelização, os problemas sociais decorrentes desse processo, sobretudo a manifestação de revolta contra o poder instituído, trouxeram sérias consequências para o cotidiano educacional.

As crianças chutavam as portas, quebravam tudo, a escola era novíssima, recém-construída, estava sendo pintada e eles acabaram com essa escola em 2004. No final do ano, não tinha uma porta com trinco, não sobrou um vidro nas janelinhas das portas. A revolta deles era contra todos. (Educ E - 02)

A primeira diretora que veio para organizar tudo, logo que percebeu a realidade, em abril ela saiu, não agüentou e pediu afastamento. Ela foi ameaçada de morte por um aluno. Ela saiu revoltada, apavorada, que pediu aposentadoria antes da hora. Essa situação de ameaça aos professores era constante. (Educ E - 02)

Essa realidade apresentada pelos docentes, no primeiro ano de funcionamento da instituição educacional, além de revelar um comportamento extremamente agressivo a ponto de praticar atos depredatórios contra a escola e atos ameaçadores contra o corpo docente, evidenciava, também, a falta de compromisso com as atividades pedagógicas propostas pelos educadores, o que pode ser considerado normal para educandos que, em sua trajetória educacional, sempre pertenceram ao grupo denominado "dos fracassados".

Aprender a conviver no novo bairro, com características completamente diferentes daquelas estabelecidas nas favelas, foi um desafio para todos os moradores, não só para as crianças e os adolescentes. A nova experiência de distinguir a rua, a calçada, os limites dos cômodos de uma casa com quintal, portões, os limites das instituições sociais instaladas no bairro, entre outros, manifestou-se, muitas vezes, como um movimento de resistência ao instituído, na medida em que, embora os barracos 
das favelas apresentassem um espaço bastante reduzido, a liberdade de ir e vir sem passar por "obstáculos" era considerada uma rotina. Assim, na instituição escolar, o aprender a respeitar os limites passa a ser uma aprendizagem corporal de espaço nessa nova realidade espacial em que as delimitações são bem acentuadas.

Isso também repercutiu no espaço educacional. A sala de aula não representava, para os educandos, um espaço de referência para a aprendizagem, consequentemente, o objeto de ensino e a prática pedagógica dos educadores não correspondiam à realidade vivenciada pelos educandos, a ponto de não conseguirem permanecer na sala de aula por tempo determinado.

Os alunos não paravam em sala de aula. Hoje você percebe que ainda temos alguns alunos que realmente não param em sala de aula, mas no início, nenhum aluno conseguia parar sentado durante cinco minutos. Mesmo porque, nas escolas que eles frequentavam antes de virem para cá, eles faziam isso (Educ E - 02).

Pode-se considerar que a permanência na instituição educacional e, especificamente, em sala de aula, está relacionada com a qualidade das ações que são desenvolvidas nesses espaçostempos ${ }^{4}$. As características dos educandos dessa comunidade, certamente, demandavam outras formas de organização e práticas pedagógicas que correspondessem, em um primeiro momento, à realidade vivenciada por eles em seu contexto e à própria experiência desenvolvida por eles a respeito do espaço.

A cultura educacional que ainda insiste em manter os educandos por um longo período de tempo dentro do mesmo espaço, limitado a uma carteira, fazendo as mesmas atividades que, nem sempre, são significativas, provoca em determinados grupos um movimento de resistência que é interpretado como "rebeldia". É necessário que tal "rebeldia" também contribua para que a instituição educacional olhe para si mesma e perceba a qualidade da ação educativa que propõe aos diferentes grupos.

Diante da situação da escola, começamos a discutir com os supervisores educacionais da Secretaria de Educação algumas alternativas para aquela escola. Uma certeza nós tínhamos: do jeito que estava não dava mais continuar. Foi quando começamos a pensar no projeto de parceria com a Fundhas para o ano letivo de 2005 como uma forma diferenciada de organização do currículo para o ciclo I do Ensino Fundamental (Educ E - 02). 
Assim, o reconhecimento de que tal estrutura não garantia à escola o desenvolvimento de sua função e, muito menos, um percurso de aprendizagem significativo para os educandos fez com que os educadores da escola rompessem com a estrutura posta e concebessem uma reestruturação curricular, em uma lógica totalmente diferenciada da proposta anteriormente, porém adequada às necessidades educacionais e sociais dos educandos.

Essa reestruturação curricular teve como ponto de partida, a partir de 2005, a parceria com uma instituição não-formal, para o desenvolvimento de uma experiência-piloto em educação integral, em que a escola se encarregaria de trabalhar com as áreas de conhecimento definidas pelos Parâmetros Curriculares Nacionais e a instituição não-formal se encarregaria de trabalhar com atividades focadas no trabalho socioeducativo-cultural.

Um primeiro aspecto a ser destacado é que a forma integrada de compreender o currículo pressupõe a possibilidade de trabalhar com os componentes curriculares, definidos nacionalmente, sem a necessidade de seguir uma mesma ordem que caracterize a estrutura lógica dos conteúdos por disciplinas. É o que podemos verificar na proposta pedagógica da escola (2005-2006), que prevê como estrutura curricular, a seguinte organização:

\section{QUADRO 2}

PROPOSTA CURRICULAR VIGENTE A PARTIR DE 2005

\begin{tabular}{c|c} 
BASE NACIONAL COMUM & CICLO I \\
HORAS / SEMANA
\end{tabular}

Embora perceba-se que Artes, Educação Física e Sala de Leitura são assumidas na estrutura curricular como áreas a serem trabalhadas separadamente dos componentes curriculares convencionais (Português, Matemática, História, Geografia, Ciências), inclusive com profissionais 
especializados, a integração dos profissionais e dos conteúdos é perceptível. Sendo assim, é possível inferir que existe a tentativa de construir um trabalho não fragmentado, em que tais áreas são tratadas com igual importância e os diferentes campos de conhecimento são considerados meios para a compreensão do contexto social, a partir dos projetos de aprendizagens que são desenvolvidos pelos educadores e educandos.

O segundo aspecto a ser destacado nessa estrutura curricular é a inserção das ações educativas, que, no projeto, são chamadas de complementares, desenvolvidas no contraturno das atividades escolares, a partir da parceria estabelecida com uma instituição não-formal, a partir de 2005, possibilitando ampliar a concepção curricular para além das áreas de conhecimento, tradicionalmente trabalhadas na escola, bem como desenhar o currículo em uma dimensão integral, objetivando o desenvolvimento dos educandos no plano físico, social, emocional, cognitivo e cultural.

Embora reconhecendo que a escola é o espaço do currículo formal, a instituição não-formal, enquanto instituição parceira, pode trabalhar com mais flexibilidade, ancorando suas atividades nas demandas emergenciais da comunidade e na possibilidade de desenvolver um programa baseado em atividades que possibilitem a expressão, a criação, a experimentação e a investigação, oportunizando, assim, a formação integral.

As ações educativas complementares desenvolvidas pela instituição não-formal apresentam o seguinte desenho curricular:

\section{QUADRO 3}

\section{COMPOSIC̣ÃO CURRICULAR DA INSTITUIC̣ÃO NÃO-FORMAL}

\begin{tabular}{c|c} 
NÚCLEOS & HORAS / SEMANA \\
\hline Arte-Educação: teatro, dança, artes plásticas, música & 15 \\
Comunicação: rádio, jornal, vídeo, fotografia, leitura & \\
Informática aplicada à educação & \\
Esporte/Lazer & \\
Educação Ambiental & \\
Higiene Pessoal e Formação de Atitudes &
\end{tabular}

Tais ações educativas complementares integradas no desenho curricular da instituição não-formal, embora sejam interpretadas no "Plano de Trabalho para o Projeto de Ensino Integral Escola - Instituição não-formal" dessa experiência como atividades de enriquecimento curricular, não são assumidas na perspectiva de complementação curricular ou como aquilo que falta a uma instituição e precisa ser adicionado por outra. 
Muito pelo contrário, são, cada vez mais, assumidas como parte de um único currículo construído no cotidiano das duas instituições, uma vez que propiciam aprendizagens que não se complementam, mas que se integram em um único processo de construção de conhecimento.

A compreensão de que as atividades desenvolvidas pelas duas instituições são provenientes de conhecimentos de natureza diferenciada, porém, com o mesmo grau de importância, e que são necessários ao desenvolvimento dos educandos é comum aos educadores de ambas as instituições. É o que evidencia o testemunho de uma educadora:

A instituição não-formal tem conteúdos específicos e os dois (formal e nãoformal) são importantes e apresentam oportunidades de aprendizagens diferentes. Nós não vamos complementar os conteúdos dados pela escola. Nós estamos desenvolvendo conteúdos que são importantes tanto quanto. Nós não complementamos o ensino escolar, mas complementamos o currículo escolar. O trabalho que é desenvolvido na instituição não-formal auxilia as aprendizagens do currículo formal. A gente acredita que essa aprendizagem vai contribuir de alguma forma na aprendizagem do educando também na escola. É uma mudança de foco (Educ F - 03).

A compreensão da integração curricular apresentada pela parceria entre as duas instituições está para além da ideia de complementação de um currículo que se mostra incompleto. Muito pelo contrário, as duas instituições são impelidas em buscar, conjuntamente, caminhos integradores, em que o conhecimento possa ser entendido como uma construção que ajude os educandos a olhar o mundo, situar-se no mundo e transformar o mundo.

Neste sentido, entende-se que o trabalho coletivo no desenvolvimento dos profissionais que atuam nas duas instituições é condição sine qua non para que o currículo integral seja construído em sua totalidade.

\section{Trabalho coletivo no desenvolvimento da profissionalidade}

A construção coletiva da profissionalidade evidencia-se, em um primeiro momento, pela composição do corpo docente da escola, que passa a ser constituído não pela atribuição de aulas na sequência natural de pontuação de carreira ou aprovação em concurso, mas, de acordo com os procedimentos da instituição não-formal, mediante um processo de 
seleção a partir da adesão dos educadores expressa pela apresentação de um projeto de trabalho e entrevista.

Os supervisores de ensino tiveram o cuidado de considerar o perfil dos professores, supostamente adequado para trabalhar com a clientela daquela realidade. O depoimento da supervisora de ensino responsável pela escola é uma ilustração desse cuidado:

O professor deveria ser selecionado. Faríamos um processo de seleção em que os interessados deveriam encaminhar uma proposta que apresentasse um perfil de professor com disposição para trabalhar de forma diferenciada, trabalhar com a necessidade dos alunos, com os interesses dos alunos, um perfil que tivesse facilidade de estabelecer vínculos afetivos com os alunos com aquelas características (Educ E - 01).

Em um segundo momento, a construção coletiva da profissionalidade é evidenciada no relacionamento estabelecido entre a direção das instituições ${ }^{5}$ entre si e os educadores, técnicos administrativos e servidores. A autoridade compartilhada é um modo escolhido por esses profissionais das instituições a fim de que a tomada de decisões seja fruto da reflexão coletiva e da partilha, uma vez que todos se sentem responsáveis pelo trabalho realizado.

No trabalho educativo não é concebido o pensamento administrativo que, em geral, deposita a responsabilidade sobre uma única pessoa que direciona as ações das demais. Muito pelo contrário, a formação educacional se faz exatamente neste compartilhamento de responsabilidades e de autonomia.

Durante o período de observação, foi muito comum presenciar os coordenadores das duas instituições compartilhando com os educadores determinados problemas cujo encaminhamento era assumido de forma coletiva.

Esse posicionamento construído pelos profissionais das duas instituições se inscreve, de uma maneira mais ampla, no que podemos chamar de construção de relações mais democráticas, uma vez que, ultrapassando as relações pautadas na hierarquia, que define posturas "mais importantes", contribui para que as interações sociais sejam horizontalmente construídas, bem como favorece que a transformação social aconteça.

As reuniões pedagógicas realizadas pelas instituições foram consideradas como o segundo momento em que se pode evidenciar a construção coletiva da profissionalidade. Nelas, a dimensão da coletividade é valo- 
rizada, uma vez que a obrigatoriedade do cumprimento desse horário não é definida de acordo com as possibilidades individuais dos educadores, como é de costume acontecer nas instituições educacionais em geral. A participação nesse horário faz parte do contrato de trabalho assumido pelos educadores e ele é realizado coletivamente, em cada instituição, em função do trabalho pedagógico construído pela mesma, o que garante a unidade no planejamento e na reflexão sobre o currículo construído nas instituições.

Assumida como espaçotempo para formação permanente dos educadores e de planejamento participativo do trabalho pedagógico, as reuniões pedagógicas apresentam-se como um momento privilegiado para o desenvolvimento coletivo da profissionalidade, uma vez que os educadores podem refletir, criticamente, sobre sua prática e, superar, com a colaboração de todos, os limites enfrentados no dia a dia.

$\mathrm{Na}$ parceria entre a instituição formal e a não-formal, a necessidade de estabelecer momentos de diálogo, de interação e formação entre os educadores das duas instituições apresentou-se como uma questão fulcral para o desenvolvimento da proposta de educação integral, uma vez que não era mais possível que cada instituição fizesse o seu melhor. Naquele contexto, era necessário integrar e construir propostas de um único trabalho educativo.

Esses momentos são efetivados em reuniões semanais com a equipe técnica das duas instituições para estreitamento dos laços, possíveis adequações do projeto, maior aproximação, conhecimento e valorização das especificidades de cada instituição e a ampliação de construções conjuntas, com ganhos e benefícios para todos, principalmente os educandos. Contudo, percebemos que a interação entre as instituições não pode ser efetivada somente no nível das equipes técnicas, a necessidade de tal interação também é expressa pelos educadores, como é percebido neste relato:

Esses dias eu estava conversando com a educadora da escola, que ela tem um trabalho lá de teatro, já faz dois anos que eu estou na unidade e agora que a gente vai conseguir fazer um trabalho em conjunto. Os educandos são os mesmos, ela tem uma peça de teatro para fazer sobre o trânsito e a gente está tentando conciliar essa atividade, como a gente vai fazer para combinar, mas é praticamente difícil trabalhar em conjunto com a escola, não por falta de vontade, mas em função da estrutura mesmo, o tempo para o planejamento não coincide. A prática do trabalho em conjunto é muito difícil. Existe toda uma intenção para isso, uma disposição para isso, mas a gente não consegue (Educ F - 04). 
Quando pensamos no desenvolvimento coletivo da profissionalidade, considerando as duas instituições como uma única realidade educacional, percebemos que as limitações são evidenciadas justamente na construção do cotidiano educacional. Ou seja, são os educadores das duas instituições, aqueles que estão diariamente com os educandos, que precisariam de momentos interativos entre si. Tais momentos requerem um olhar para a estrutura organizativa das instituições a fim de que esse espaçotempo seja garantido na própria organização da educação integral, e não em situações pontuais, cuja iniciativa, geralmente, parte dos educadores fora de seu horário de trabalho.

Assim, entender e experienciar a profissionalização compartilhada entre os educadores apresenta-se como consequência decisiva na construção do currículo no cotidiano educacional, uma vez que a unidade de transformação é a instituição educacional como um todo, e não as "aulas" e as experiências profissionais individualizadas, em separado.

\section{Considerações finais}

A análise dos movimentos para a construção do currículo de uma Escola de Tempo Integral no contexto educacional formado pela parceria de duas instituições, formal e não-formal, realizada a partir da organização do currículo e do desenvolvimento coletivo da profissionalidade indicaram possibilidades que podem contribuir para o avanço das reflexões curriculares no que diz respeito à Escola de Tempo Integral e à Educação Integral.

Ao deparar-se, por um lado, com a legislação que prevê o aumento gradativo da permanência do aluno na escola e, por outro lado, com os limites espaciais e temporais da escola, a experiência da parceria com outras instituições que permitem uma articulação efetiva com a escola, como foi o caso analisado, é possível na medida em que a concepção ampliada de currículo é assumida pelas instituições parceiras. Dessa forma, algumas constatações foram feitas.

A primeira constatação diz respeito ao processo de reflexão desenvolvido pelos educadores da escola, enquanto instituição formal, sobre sua ação educativa com aqueles educandos. Tal reflexão contribui para a tomada de consciência de que a escola não pode tudo em termos 
educacionais, pelas próprias limitações do sistema, da estrutura, da organização do espaço e do tempo, do regime de trabalho dos educadores, da formação desses educadores.

A segunda constatação evidencia que é possível estabelecer parceria com um objetivo comum entre as duas instituições, embora elas apresentem particularidades, filosofias, divergências, formas diferenciadas de compreender e trabalhar com o processo educacional. Contudo é necessário compreender que a natureza da aprendizagem é diferente em cada instituição, consequentemente, as atividades desenvolvidas por cada uma delas.

A terceira constatação nos aponta que a educação integral só pode ser consolidada a partir da concepção, ampliada e expandida, de um currículo que pode integralizar em si a dimensão formal e não-formal da educação como dimensões articuladas que não se sobreponham às diferenças de natureza do conteúdo, da metodologia e do conhecimento trabalhadas tanto na dimensão formal quanto na dimensão não-formal da educação. Dessa forma, é possível fazer a integração entre as duas instituições.

A quarta constatação nos aponta que a integração, de fato, acontece quando, no cotidiano, as ações realizadas pelas duas instituições são compartilhadas para o mesmo objetivo, que é o desenvolvimento dos educandos.

Esta análise também evidencia alguns desafios que devem ser superados na construção do currículo para a Escola de Tempo Integral com uma perspectiva de Educação Integral. São eles:

- Uma legislação que garanta a Educação Integral para todos e não apenas para algumas experiências específicas e pontuais.

- Uma política de financiamento que garanta as necessidades provenientes da Educação Integral, sobretudo na necessidade de o tempo integral também ser considerado para o professor.

- A construção de um corpo conceitual que sustente a concepção de currículo da Educação Integral para além da expansão do tempo na escola.

- A formação de profissionais para entender e desenvolver ações educativas em perspectivas mais amplas que a escola.

O enfrentamento desses desafios faz-se necessário para que a Escola de Educação Integral possa ser configurada na dimensão da Educação Integral como um direito de todos os cidadãos brasileiros em idade escolar. 


\section{REFERÊNCIAS}

ALVES, Nilda. O espaço escolar e suas marcas: o espaço escolar como dimensão material do currículo. Rio de Janeiro: D, P \& A, 1998.

APPLE, Michael W. Ideologia e Currículo. 3 ed. Porto Alegre: Artmed, 2006.

ARANTES, Valéria Amorim (Org.). Educação formal e não-formal. São Paulo: Summus, 2008.

BRASIL. Lei n. 9.394, de 20 de dezembro de 1996. Dispõe sobre as Diretrizes e Bases da Educação Nacional. Diário Oficial da União, Brasília, DF, 23 dez. 1996.

BRASIL. Decreto n. 7.083, de 27 de janeiro de 2010. Dispõe sobre o Programa Mais Educação. Diário Oficial da União, Brasília, DF, 27 de janeiro de 2010.

CASTORIADIS, C. A instituição imaginária da sociedade. 3 ed. Rio de Janeiro: Paz e Terra, 1995.

COELHO, L. M. Educação integral: concepções e práticas na educação fundamental. In: REUNIÃO ANUAL DA ANPEd, 27. Caxambu, 2004. Disponível em:

<http://www.anped.org.br/reunioes/27/gt13/t137.pdf>. Acesso em: 16 jul. 2009.

COELHO, L. M. História (s) da Educação Integral. In: MAURÍCIO, Lúcia V. (Org.). Educação Integral e Tempo Integral. Brasília: INEP: Em Aberto, v. 22, n. 80, abr 2009.

GIROUX, Henry A.; SIMON, Roger. Cultura Popular e a Pedagogia Crítica: A vida cotidiana como base para o conhecimento curricular. In: MOREIRA, A. F.; SILVA, T. T. da. Currículo, Cultura e Sociedade. 5 ed. São Paulo: Cortez, 2001.

GONÇALVES, Antonio Sérgio; PETRIS, Liliane. Escola de Tempo Integral - A construção de uma proposta. Disponível em:

$<$ http://www.nexusassessoria.com.br/downloads/ETI_a_construcao_de_uma_proposta.pdf > . Acesso em: 20 ago. 2009.

GOODSON, Ivor F. Currículo: Teoria e História. 8 ed. Petrópolis, RJ: Vozes, 2008.

GUARÁ, Isa M. F. R. Educação e desenvolvimento integral: articulando saberes na escola e além da escola. IN: MAURÍCIO, Lúcia V. (Org.). Educação Integral e Tempo Integral. Brasília: INEP: Em Aberto, v. 22, n. 80, abr. 2009.

MOLL, Jaqueline. Educação Integral e reinvenção da escola: Elementos para o debate a partir do programa Mais Educação. In: DALBEN, Ângela I. L. de F. et al. Convergências e tensões no campo da formação e do trabalho docente. Belo Horizonte: Autêntica, 2010.

MOREIRA, Antonio Flavio B. Currículos e programas no Brasil. 13 ed. Campinas, SP: Papirus, 2006.

MOREIRA, A. F.; SILVA, T. T. da. Currículo, cultura e sociedade. 5 ed. São Paulo: Cortez, 2001. OLIVEIRA, Inês Barbosa de. As Artes do Currículo. In: OLIVEIRA, Inês Barbosa de (Org.). Alternativas emancipatórias em currículo. São Paulo: Cortez, 2004.

PIRES, Clarice. Referências para um currículo crítico-emancipatório na universidade: Construindo o projeto educativo do Centro Universitário de Brusque-SC. Tese (Doutorado) Pontifícia Universidade Católica, São Paulo, 2005.

SACRISTÁN, J. G. O Currículo: Uma reflexão sobre a prática. 3 ed. Porto Alegre: Artmed, 2000.

SOUZA, Danilo de Melo. Educação Integral em Palmas no Tocantins: Implantação e Sustentabilidade. In: DALBEN, Ângela I. L. de F. et al. Convergências e tensões no campo da formação e do trabalho docente. Belo Horizonte: Autêntica, 2010.

TRILLA, Jaume. A educação não-formal. In: ARANTES, Valéria Amorim (Org.). Educação formal e não-formal. São Paulo: Summus, 2008. 


\section{NOTAS}

1 Trata-se das instituições públicas de ensino fundamental criadas pelo governador Leonel Brizola (CIEPs), no estado do Rio de Janeiro, e pelo presidente Fernando Collor de Melo (CAICs), visando ao desenvolvimento de uma educação em tempo integral.

2 O contraturno é entendido como o período contrário ao que os alunos frequentam a escolarização regular. Por exemplo, se o aluno frequenta a escola no período matutino, o período vespertino é considerado como contraturno e vice-versa.

3 A Unidade da Fundhas (Fundação Hélio Augusto de Souza) é a instituição não-formal participante desta pesquisa, sem fins lucrativos, que propõe atividades socioeducativacultural para crianças e adolescentes, durante o contraturno escolar.

4 Optamos por utilizar a expressão espaçotempo no texto deste trabalho por entendê-lo a partir de Nilda Alves, que cunhou essa expressão, como dimensão material do currículo que se entrelaça e deve ser assumindo em sua multiplicidade e complexidade (ALVES, 1998).

5 Denomino de direção das instituições todos os papéis assumidos por diferentes profissionais que não estão diretamente em sala de aula. A saber: diretora, vice-diretora, gestor da unidade, orientadora pedagógica, orientadora educacional.

Recebido: $15 / 07 / 2010$

Aprovado: 25/05/2011

Contato:

Rua Aggeu Gomes da Silva, 225

Jardim Aeroporto CEP $37130-000$

Alfenas, MG

Brasil 